\title{
Adsorption of Copper, Nickel, and Cadmium on Goethite in the Presence of Organic Ligands
}

\author{
DIANE BUERGE-WEIRICH ${ }^{1}$, PHILIPPE BEHRA ${ }^{2}$ and LAURA SIGG $^{1 \star}$ \\ ${ }^{1}$ Swiss Federal Institute for Environmental Science and Technology (EAWAG), $\mathrm{CH}$ \\ 8600-Duebendorf Switzerland; ${ }^{2}$ Institut de Mécanique des Fluides et des Solides, UMR 7507 \\ Université Louis Pasteur-CNRS, 2, rue Boussingault, 67000 Strasbourg, France (Present address: \\ Ecole Nationale Supérieure des Ingénieurs en Arts Chimiques et Technologiques, Laboratoire de \\ Chimie Agro-Industrielle, UMR 1010 INRA/INP-ENSIACET, 118, route de Narbonne, 31077 \\ TOULOUSE Cedex 4, France)
}

(Received 28 January 2003; accepted 25 September 2003)

\begin{abstract}
Adsorption of copper, cadmium and nickel at low concentrations on goethite was studied in the presence of the simple organic ligands oxalate, salicylate, and pyromellitate. The experimental metal adsorption behavior was compared to calculations with a surface complexation model to evaluate the most important interactions. Oxalate mostly decreased $\mathrm{Cu}$ and $\mathrm{Ni}$ adsorption at high $\mathrm{pH}-$ values by competition between solution and surface complexation but had no effect on Cd adsorption. $\mathrm{Cu}$ adsorption in the presence of oxalate below $\mathrm{pH} 6$ could best be described by defining a ternary complex of type A (surface-metal-ligand). Salicylate had only minor effects on metal adsorption. The adsorption of $\mathrm{Cu}$ in the presence of salicylate above $\mathrm{pH} 5$ could be explained by a ternary complex of type A. Pyromellitate increased the adsorption of $\mathrm{Cu}$ and $\mathrm{Cd}$ in the acidic $\mathrm{pH}$-range, likely by formation of ternary surface complexes of type B (surface-ligand-metal).
\end{abstract}

Key words: copper, cadmium, nickel, ternary complex, oxalate, salicylate, pyromellitate, goethite, surface complexation

\section{Introduction}

Natural organic ligands have an important influence on the transport of heavy metals in soils and infiltration groundwater systems (Stumm, 1996; Stumm and Morgan, 1996; von Gunten et al., 1991; von Gunten and Kull, 1986; von Gunten and Lienert, 1993). A variety of models has been developed to describe the complexation and adsorption properties of natural organic substances with high molecular weight (Bartschat et al., 1992; Benedetti et al., 1995; Dzombak et al., 1986; Tipping, 1986, 1993, 1994; Tipping and Hurley, 1992; Tipping and Woof, 1990). However, a detailed, quantitative description is still difficult as the knowledge about structure, chemical, and electrostatic behavior of humic substances and hydrophilic acids is still quite limited. Organic ligands of lower molecular weight with carboxylic groups and/or phenolic groups, which represent major functional

\footnotetext{
^ Author for correspondence. E-mail: sigg@eawag.ch
} 
groups in natural organic ligands (Aiken et al., 1985; Stevenson, 1982), may serve as simple models to investigate the chemical interactions between metals, ligands, and surfaces. They can form innersphere or outersphere surface complexes, which have been shown to be important at $\mathrm{pH}$ values below $\mathrm{pH}_{\mathrm{pzc}}$ ( $\mathrm{Gu}$ et al., 1994). Although simple organic ligands cannot represent the electrostatic properties of humic substances, they are in a first approach useful as model compounds (Ali and Dzombak, 1996a) to represent various structure elements of organic matter.

In this study, oxalate, salicylate, and pyromellitate were chosen as simple organic ligands. These compounds have been often used in the literature to represent certain properties of natural organic matter (Davis and Leckie, 1978; Evanko and Dzombak, 1998). A direct comparison of the adsorption behavior between these ligands and several heavy metals is however not available in the literature. Oxalic acid (ethanedioic acid) is generally selected to represent the aliphatic part of humic substances (Elliott and Denneny, 1982; Filius et al., 1997; Huang, 1977; Lamy et al., 1991; Violante et al., 1996). Oxalate is one of the most abundant organic ligands of low molecular weight in soils and is particularly concentrated in the rhizosphere. Salicylic acid (2-hydroxybenzoic acid) is an important structural unit of dissolved humic substances and is important to define acidity and complexation properties of fulvic acids (Leenheer et al., 1995). Pyromellitic acid (1,2,4,5benzenetetracarboxylic acid) is a good chelating agent with four carboxylic groups located on both sides of the benzene ring. Pyromellitate has been used in the last few years as a representative for natural organic ligands in several studies (Angove et al., 1999; Evanko and Dzombak, 1998).

These three ligands can be expected to represent quite a broad range of possible influences of natural organic ligands on the adsorption of heavy metals on goethite. Oxalate is a strong complexing agent and is therefore likely to compete with the surface groups to complex heavy metals at elevated $\mathrm{pH}$ values. Formation of ternary surface complexes (surface-ligand-metal) in the acidic $\mathrm{pH}$ range can be expected with pyromellitate. Both types of reactions are not expected with salicylate. It is a less strong ligand and competitive reactions with the surface are not likely at the surface/ligand concentration ratios used in this study.

The objective of this work is to present metal adsorption data at low metal concentrations on a variation of systems, i.e., variation of the metal ion and the ligand. The three ligands are compared with regard to their effects on metal adsorption, namely either decrease in adsorption by competition with complexation in solution, or increase of adsorption by electrostatic or specific interactions at the surface. Simple calculations, based on the surface complexation model (double layer model, DLM), are performed to exemplify the major influences of a ligand on metal adsorption. These results are discussed critically, especially with regard to the possible formation of ternary complexes. 


\section{Experimental Conditions}

\subsection{CHEMICALS}

Metal solutions were prepared from metal stock standard solutions from Baker Analyzed ${ }^{\circledR}\left(\mathrm{Cu}, \mathrm{Ni}, \mathrm{Cd}: 1000 \mu \mathrm{g} / \mathrm{mL}\right.$ Baker Instra-Analyzed $\left.{ }^{\circledR}\right)$. Following chemicals were from Fluka: Biochemika grade: HEPES (4-(2-hydroxyethyl)-piperazine1-ethane-sulfonic acid), MES (2-morpholinoethane-sulfonic acid monohydrate), and oxalic acid sodium salt; Chemika grade: sodium salicylate. $\mathrm{KNO}_{3}$ was used from Merck suprapur ${ }^{\circledR}$ and pyromellitic acid from Merck (synthesis grade).

All nitric acid dilutions were prepared from $\mathrm{HNO}_{3} 65 \%$, Merck suprapur ${ }^{\circledR}$. All $\mathrm{NaOH}$ dilutions were prepared $\mathrm{CO}_{2}$-free from $50 \% \mathrm{NaOH}$ solutions (Baker Analyzed ${ }^{\circledR}$. In such solutions, carbonate precipitates as $\mathrm{Na}_{2} \mathrm{CO}_{3}$ and can thus be eliminated by filtration (Öhman and Sjöberg, 1996). The polypropylene bottles and the nanopure water used for the dilutions were purged prior to use with argon and nitrogen, respectively. No glassware was used during the whole manipulation to avoid silica contamination. In order to prevent the $\mathrm{NaOH}$ solution to be exposed to air, mixing as well as storage was done under argon atmosphere. $\mathrm{NaOH}$ solutions were only used for $24 \mathrm{~h}$.

Goethite was purchased from BASF and was washed with $\mathrm{CO}_{2}$-free $10^{-3} \mathrm{M}$ $\mathrm{NaOH}$ and $10^{-3} \mathrm{M} \mathrm{HNO}_{3}$ before use. Details to the washing procedure are given elsewhere (Weirich, 2000). The site density was defined to be 1.3 sites $/ \mathrm{nm}^{2}$ and the specific surface area was measured by the BET method $\left(\mathrm{N}_{2} 77 \mathrm{~K}\right)$ to be $21.4 \mathrm{~m}^{2} / \mathrm{g}$ (Ehrhardt, 1999; Weirich, 2000). By scanning electron microscopic studies (SEM), the crystal morphology of this goethite was deduced to have the form of needles (Ehrhardt, 1999; Weirich, 2000). The dimensions of these needles are $1000 \times 150$ $\times 30 \mathrm{~nm}$. The pores of this goethite are to $40 \%$ between 33 and $97 \mathrm{~nm}$ (Ehrhardt, 1999), which means that this goethite was highly crystallized. ICP-OES measurements showed that certain impurities ( $\mathrm{Ba}, \mathrm{Ca}, \mathrm{Cu}, \mathrm{Mg}, \mathrm{Mn}, \mathrm{Na}, \mathrm{Sr}, \mathrm{Ti})$ are present in this goethite. Anions like sulfate have been detected by X-Ray Photoelectron Spectroscopy (XPS) analyses (Ehrhardt, 1999; Morsad, 1999). Extensive washing removed these impurities (Morsad, 1999). The goethite was stored in suspensions of $20 \mathrm{~g} / \mathrm{L}$. Before use, goethite suspensions were thoroughly shaken. Pipetting of goethite into the bottles used for the experiments was done with an error smaller than $4 \%$.

All solutions were prepared with deionized water $\left(18 \mathrm{M} \Omega \mathrm{Q}-\mathrm{H}_{2} \mathrm{O}\right.$ grade Barnstead Nanopure) in bottles soaked for at least $24 \mathrm{~h}$ in $0.1 \mathrm{M} \mathrm{HNO}_{3}$. They were purged with nitrogen in order to remove $\mathrm{CO}_{2}$. For metal, $\mathrm{NaOH}$, and HEPES solutions, polypropylene bottles were used. Goethite suspensions were stored in polyethylene bottles. All other solutions were prepared and stored in glassware. 


\subsection{GENERAL EXPERIMENTAL SETUP}

Batch experiments were performed at $25{ }^{\circ} \mathrm{C}$ in $100 \mathrm{~mL}$ polypropylene bottles, soaked for at least $24 \mathrm{~h}$ in $0.1 \mathrm{M} \mathrm{HNO}_{3}$ and rinsed before use with nanopure water. Because of possible photoreduction of goethite by organic ligands, experiments were carried out under red light $(\lambda>560 \mathrm{~nm}$ ) (Siffert and Sulzberger, 1991; Sulzberger et al., 1989). During the experimental work, all care was taken to remove $\mathrm{CO}_{2}$ (Weirich, 2000).

The ionic strength was adjusted to $0.01 \mathrm{M}$ with $\mathrm{KNO}_{3} \cdot \mathrm{pH}$ between 5.2 and 7.2 was buffered with MES (concentration $5 \mathrm{mM}$ ) and between $\mathrm{pH} 7.2$ and 7.8 with HEPES (concentration: $5 \mathrm{mM}$ ). Below pH 5.2 and above $\mathrm{pH} 7.8$, no buffers were used and the $\mathrm{pH}$ was adjusted by adding $\mathrm{HNO}_{3}$ and $\mathrm{NaOH}$, respectively. It has been shown that impurities in HEPES can complex copper (Mash et al., 2003). However, in our system with high ligand concentration (dissolved organic and surface ligands), this effect can be neglected. Moreover, HEPES was used in experiments with and without organic ligands. $\mathrm{pH}$ was measured with an Orion combination electrode (Ross electrode, type 81.02) connected to an Orion $\mathrm{pH}$ meter (type 420A). The electrode was calibrated with three $\mathrm{pH}$ buffers from Hamilton Bonaduz Ag with pH $4.01 \pm 0.02,7.00 \pm 0.02,9.21 \pm 0.02$.

The metal and the ligand were equilibrated for $30 \mathrm{~min}$ at the desired $\mathrm{pH}$ value and ionic strength. Afterwards, goethite was added and the samples were allowed to react in the dark for $4 \mathrm{~h}$. All conditions are reported in Table I. After the final equilibration step, the $\mathrm{pH}$ was measured in the suspension under nitrogen atmosphere. This equilibrium $\mathrm{pH}$ value, which was slightly lower than that before the adsorption reaction, was used for data evaluation. Afterwards, the samples were filtered $(0.45 \mu \mathrm{m}$, either Acrodisc Gelman Science or Titan Nylon from Schmidlin Labor \& Service AG) and acidified to $0.01 \mathrm{M} \mathrm{HNO}_{3}$ for metal analysis. For oxalate analysis, the $\mathrm{pH}$ of the filtrate was set to $\mathrm{pH} 10$. The concentration of metal or ligand adsorbed was calculated from the difference between the total initial concentration and the measured concentration in the filtrate after the adsorption reaction. Total metal concentrations in the filtrate were measured with ICP-OES (Spectroflame). Analytical methods were checked with standard addition in the matrix. The detection limits were the following: $\mathrm{Cu}: 7.8 \times 10^{-8} \mathrm{M}, \mathrm{Cd}: 8.9 \times 10^{-8}$ $\mathrm{M}$, Ni: $8.5 \times 10^{-7} \mathrm{M}$. Oxalate concentrations in the filtrate were measured by ion chromatography (Dionex, column As 11).

Reference samples without organic ligands were measured in a simple ionic medium $\left(0.01 \mathrm{M} \mathrm{KNO}_{3}\right)$.

Blanks of filters, bottles, and goethite suspensions were checked for possible contamination problems. No problems arose for the concentration ranges used in this study. 
Table I. Experimental conditions used in the experiments

\begin{tabular}{ll}
\hline $\mathrm{pH}$ & $2-9$ \\
Metal $^{\mathrm{a}}[\mathrm{M}]$ & $5 \times 10^{-6}$ \\
Ligand $^{\mathrm{b}}[\mathrm{M}]$ & $5 \times 10^{-4}$ \\
goethite $^{\mathrm{g} / \mathrm{L}]}$ & 0.5 \\
$\mathrm{I}[\mathrm{M}]^{\mathrm{c}}$ & 0.01 \\
Buffer $^{\mathrm{d}}[\mathrm{M}]$ & $5 \times 10^{-3}$ \\
\hline
\end{tabular}

${ }^{\mathrm{a}} \mathrm{Cu}, \mathrm{Cd}$, or $\mathrm{Ni}$.

${ }^{\mathrm{b}}$ Oxalate, salicylate, or pyromellitate.

${ }^{c}$ Ionic strength adjusted with $\mathrm{KNO}_{3}$.

$\mathrm{d}$ MES or HEPES.

\section{Calculations}

\subsection{METAL ADSORPTION ON GOETHITE IN THE ABSENCE OF ORGANIC LIGANDS}

The acidity constants for this goethite have been determined by Morsad (1999). Modeling of metal adsorption was performed with the surface complexation model (SCM) together with the double layer model (DLM) to account for electrostatic interactions. Only experimental data below $90 \%$ metal adsorption were used, because large errors are involved at higher adsorption. Parameters were estimated with the program FitEQL (Herbelin and Westall, 1994). The relative error of the total metal concentration was fixed to $10 \%$ and the absolute error of the total metal concentration was defined to be $10 \%$ of the initial total metal concentration (Dzombak and Morel, 1990). The goodness of fit was checked by the WSOS/DF factor (weighted sum of squares divided by the degree of freedom). It was also checked that the actual error in the metal mass balance was approximately equal to the defined experimental error, and that the quotient of both was randomly varying around 1 for all data points to make sure that the model was appropriate.

One surface species each was used to describe the adsorption-edge of $\mathrm{Cu}$, $\mathrm{Cd}$, and $\mathrm{Ni}$ on goethite (Equations (1)-(3)). The species that were used for the estimation of the adsorption constants are all listed in Table II.

$$
\begin{aligned}
& \equiv \mathrm{Fe}-\mathrm{OH}+\mathrm{Cu}^{2+} \Leftrightarrow \equiv \mathrm{Fe}-\mathrm{O}-\mathrm{Cu}^{+}+\mathrm{H}^{+} \quad \log K_{\mathrm{Cu}, \text { ads }}=0.71, \\
& \equiv \mathrm{Fe}-\mathrm{OH}+\mathrm{Cd}^{2+} \Leftrightarrow \equiv \mathrm{Fe}-\mathrm{O}-\mathrm{Cd}^{+}+H^{+} \quad \log K_{\mathrm{Cd}, \text { ads }}=-1.47, \\
& \equiv \mathrm{Fe}-\mathrm{OH}+\mathrm{Ni}^{2+} \Leftrightarrow \equiv \mathrm{Fe}-\mathrm{O}-\mathrm{Ni}^{+}+H^{+} \quad \log K_{\mathrm{Ni}, \text { ads }}=-0.52,
\end{aligned}
$$




\subsection{ADSORPTION OF THE ORGANIC LIGANDS}

As for the metal adsorption, description of the ligand adsorption was performed with the SCM together with the DLM to account for electrostatic interactions.

Adsorption of oxalate was modeled from our measurements, using two surface species, as follows. More details are given elsewhere (Weirich, 2000).

$\equiv \mathrm{Fe}-\mathrm{OH}+\mathrm{Ox}^{2-}+\mathrm{H}^{+} \Leftrightarrow \equiv \mathrm{Fe}-\mathrm{Ox}^{-}+\mathrm{H}_{2} \mathrm{O} \quad \log K_{\mathrm{Ox}, 1}=12.95$,

$\equiv \mathrm{Fe}-\mathrm{OH}+\mathrm{Ox}^{2-}+2 \mathrm{H}^{+} \Leftrightarrow \equiv \mathrm{Fe}-\mathrm{OxH}+\mathrm{H}_{2} \mathrm{O} \quad \log K_{\mathrm{Ox}, 2}=18.14$.

Adsorption of salicylate and pyromellitate were not measured in our system. However, calculations in these systems could be performed by using data from the literature, which were determined under a similar ligand/goethite ratio as in our study (Evanko and Dzombak, 1999). Modeling was performed with the generalized two layer model (Dzombak and Morel, 1990). However, no difference between strong and weak adsorption sites was made, so this model is identical to the DLM and the constants could be used directly. For salicylate adsorption, two surface species were defined (Evanko and Dzombak, 1999) and for pyromellitate adsorption, six different surface species had to be defined (Evanko and Dzombak, 1999). All species were defined as in the publication of Evanko and Dzombak (Evanko and Dzombak, 1999).

$$
\begin{aligned}
& \equiv \mathrm{Fe}-\mathrm{OH}+\mathrm{HSal}^{-}+\mathrm{H}^{+} \Leftrightarrow \equiv \mathrm{Fe}-\mathrm{HSal}+\mathrm{H}_{2} \mathrm{O} \quad \log K_{\mathrm{Sal}, 1}=8.55, \\
& \equiv \mathrm{Fe}-\mathrm{OH}+\mathrm{HSal}^{-} \Leftrightarrow \equiv \mathrm{FeO}-\mathrm{Sal}^{3-}+2 \mathrm{H}^{+} \quad \log K_{\mathrm{Sal}, 2}=-12.92, \\
& \equiv \mathrm{Fe}-\mathrm{OH}+\mathrm{H}_{3} \mathrm{Pyr}^{-}+\mathrm{H}^{+} \Leftrightarrow \equiv \mathrm{Fe}-\mathrm{H}_{3} \mathrm{Pyr}+\mathrm{H}_{2} \mathrm{O} \quad \log K_{\mathrm{Pyr}, 1}=11.91 \text {, } \\
& \equiv \mathrm{Fe}-\mathrm{OH}+\mathrm{H}_{3} \mathrm{Pyr}^{-} \Leftrightarrow \equiv \mathrm{Fe}-\mathrm{H}_{2} \mathrm{Pyr}^{-}+\mathrm{H}_{2} \mathrm{O} \quad \log K_{\mathrm{Pyr}, 2}=9.15 \text {, } \\
& \equiv \mathrm{Fe}-\mathrm{OH}+\mathrm{H}_{3} \mathrm{Pyr}^{-} \Leftrightarrow \equiv \mathrm{Fe}-\mathrm{HPyr}^{2-}+\mathrm{H}^{+}+\mathrm{H}_{2} \mathrm{O} \quad \log K_{\mathrm{Pyr}, 3}=4.70, \\
& \equiv \mathrm{Fe}-\mathrm{OH}+\mathrm{H}_{3} \mathrm{Pyr}^{-} \Leftrightarrow \equiv \mathrm{Fe}-\mathrm{Pyr}^{3-}+2 \mathrm{H}^{+}+\mathrm{H}_{2} \mathrm{O} \\
& =\log K_{\mathrm{Pyr}, 4}-1.25 \text {, } \\
& \equiv \mathrm{Fe}-\mathrm{OH}+\mathrm{H}_{3} \mathrm{Pyr}^{-} \Leftrightarrow \equiv \mathrm{FeOH}-\mathrm{Pyr}^{4-}+3 \mathrm{H}^{+} \quad \log K_{\mathrm{Pyr}, 5}=-6.61 \text {, } \\
& \equiv \mathrm{Fe}-\mathrm{OH}+\mathrm{H}_{3} \mathrm{Pyr}^{-} \Leftrightarrow \equiv \mathrm{FeO}-\mathrm{Pyr}^{5-}+4 \mathrm{H}^{+} \quad \log K_{\mathrm{Pyr}, 6}=-13.12 .
\end{aligned}
$$

\subsection{ADSORPTION OF METAL IONS IN THE PRESENCE OF ORGANIC LIGANDS}

Metal adsorption on goethite in the presence of organic ligands was estimated by the two following approaches: 
In approach 1, only competition between metal surface adsorption and complexation in solution by the ligand is considered. Both the adsorption of the metal and of the ligand on goethite and the complexation in solution are taken into account in the calculations. The goethite surface becomes more negatively charged because of the ligand adsorption, which can increase metal adsorption.

In approach 2, additional interactions between metal and ligand at the goethite surface are considered, by including the formation of ternary surface complexes of type A (metal-like) or type B (ligand-like) (Equations (14) and (15)).

Type $\mathrm{A}: \equiv \mathrm{Fe}-\mathrm{OH}+\mathrm{Me}^{2+}+\mathrm{L}^{x-} \Leftrightarrow \equiv \mathrm{Fe}-\mathrm{O}-\mathrm{Me}-\mathrm{L}^{(x-1)-}+\mathrm{H}^{+}$,

Type B: $\equiv \mathrm{Fe}-\mathrm{OH}+\mathrm{Me}^{2+}+\mathrm{L}^{x-}+\mathrm{H}^{+} \Leftrightarrow \equiv \mathrm{Fe}-\mathrm{L}-\mathrm{Me}^{(x-3)-}$

$$
+\mathrm{H}_{2} \mathrm{O} \text {. }
$$

The goal of this approach was to discuss which type of ternary surface complex was likely to occur. Calculations were performed over a range of constants, which allowed seeing how the shape of the adsorption-edges was changed with the definition of a ternary surface complex. Only the adsorption-edges calculated with the reactions and constants that could best represent the data are shown in the figures.

Calculations were performed with the speciation program ChemEQL (Müller, 1996). The constants used for modeling are reported in Table II. Constants for Ni-pyromellitate complexes could not be found in the literature.

\section{Results}

\subsection{INFLUENCE OF OXALATE ON THE ADSORPTION OF CU, NI, AND CD ON GOETHITE (FIGURES 1-3)}

The adsorption-edge of $\mathrm{Cu}$ is shifted to the right in the presence of oxalate, which is a hint to the presence of competitive reactions for complexation of $\mathrm{Cu}$ between the oxalate in solution and the goethite surface functional groups (Figure 1). The calculations (approach 1) confirm this competition, as the calculated adsorptionedge of $\mathrm{Cu}$ in the presence of oxalate is shifted to the right. However, the calculated adsorption-edge is much steeper than the experimental one. This difference is due to the surface reaction used and its associated proton stoichiometry. By addition of a ternary surface complex of type A (approach 2$)\left(\log K_{\text {ter,A }}=9\right)$, the surface reaction stoichiometry is changed, and the experimental points at $\mathrm{pH}$ values below 6 could be described. Overall, a better description of the $\mathrm{pH}$ adsorption-edge was not possible within our simple assumptions.

In the presence of oxalate, at $\mathrm{pH}$ values above 7 , a decrease in $\mathrm{Ni}$ adsorption was observed, whereas, at $\mathrm{pH}$ values lower than 7 , no influence of oxalate on Ni adsorption could be observed directly from the experimental adsorption-edges (Figure 2). The change in the slope of the adsorption-edge of $\mathrm{Ni}$ in the presence of oxalate, 


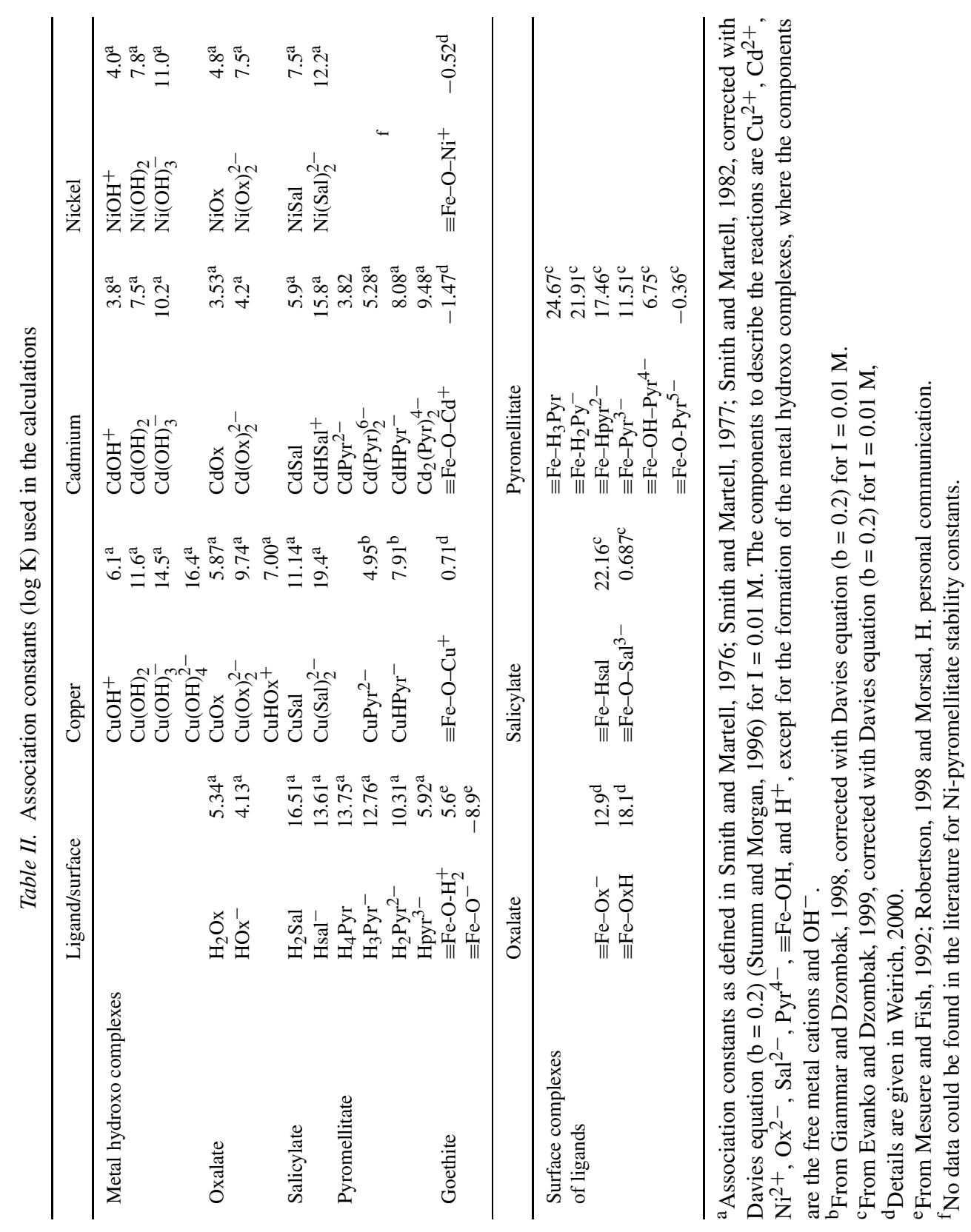




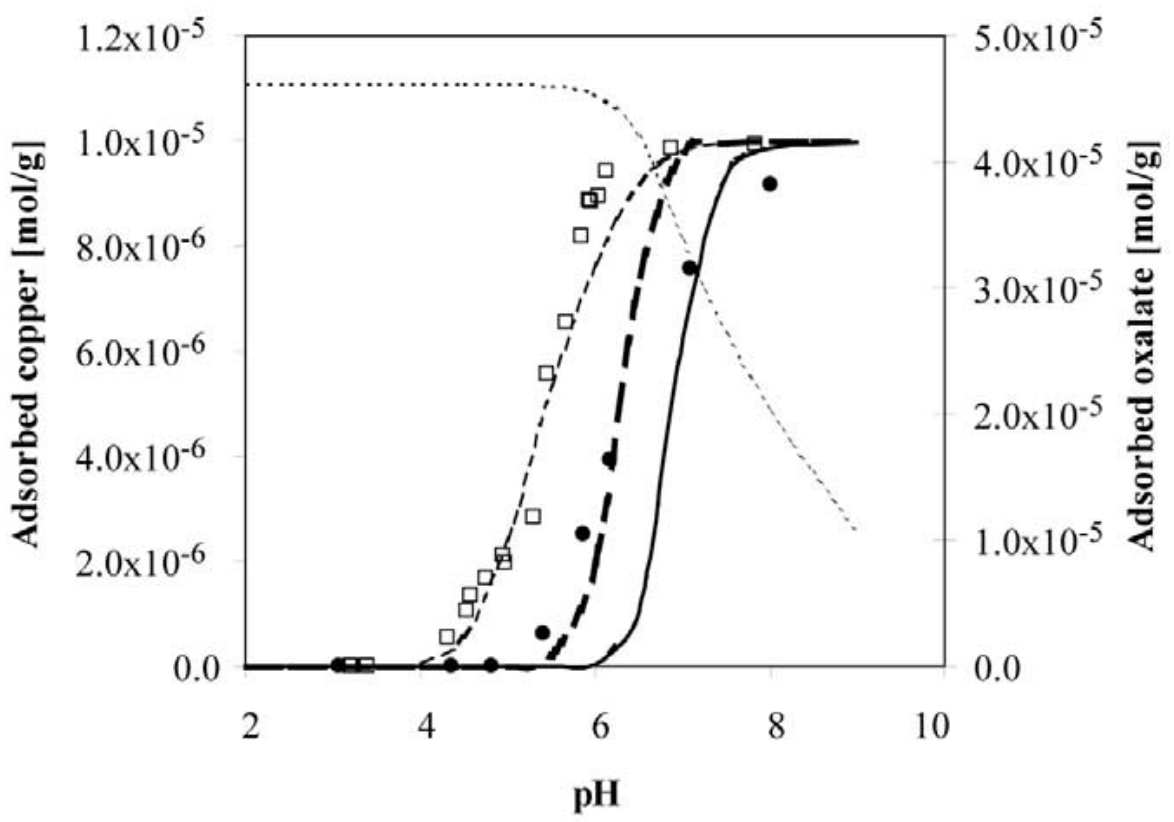

Figure 1. pH adsorption-edge of $\mathrm{Cu}$ on goethite in the presence of oxalate $(\mathbf{)})$. For comparison, a reference experiment in $0.01 \mathrm{M} \mathrm{KNO}_{3}(\square)$, calculated with the SCM and the DLM $(---)$ is shown. The calculated oxalate adsorption-edge in the presence of copper is also shown (-- - -). Cu adsorption in the presence of oxalate was calculated by approach 1 (-). The formation of the ternary surface complex of type $\mathrm{A}, \equiv \mathrm{Fe}-\mathrm{O}-\mathrm{Cu}-\mathrm{Ox}{ }^{-}$(approach 2), was assumed and the adsorption-edge was calculated with the adsorption constant log $\left.\mathrm{K}_{\mathrm{ter}, \mathrm{A}}=9(---)\right)$.

however, indicates a change in the adsorption mechanism of $\mathrm{Ni}$ : in the presence of oxalate, less protons are released per adsorbed $\mathrm{Ni}$. The poor description of $\mathrm{Ni}$ adsorption is due to the surface reaction defined. Furthermore, as Ni complexation kinetics can be supposed to be slower than $\mathrm{Cu}$ or $\mathrm{Cd}$ complexation kinetics, $\mathrm{Ni}$ adsorption may not have reached an equilibrium state after $4 \mathrm{~h}$ reaction, thus kinetic problems may additionally be responsible for the poor model description.

No significant influence of oxalate on $\mathrm{Cd}$ adsorption could be observed. Adsorption could be considered as slightly enhanced in the $\mathrm{pH}$ range of about 6 to 7 , but it was not clearly decreased at higher $\mathrm{pH}$ values (Figure 3 ). Here as well, the calculated adsorption-edge is too steep compared to the experimental one. For $\mathrm{Cd}$ this problem is well known in the literature and more complicated assumptions are needed to explain its adsorption (Boily, 1999; Venema et al., 1996). 


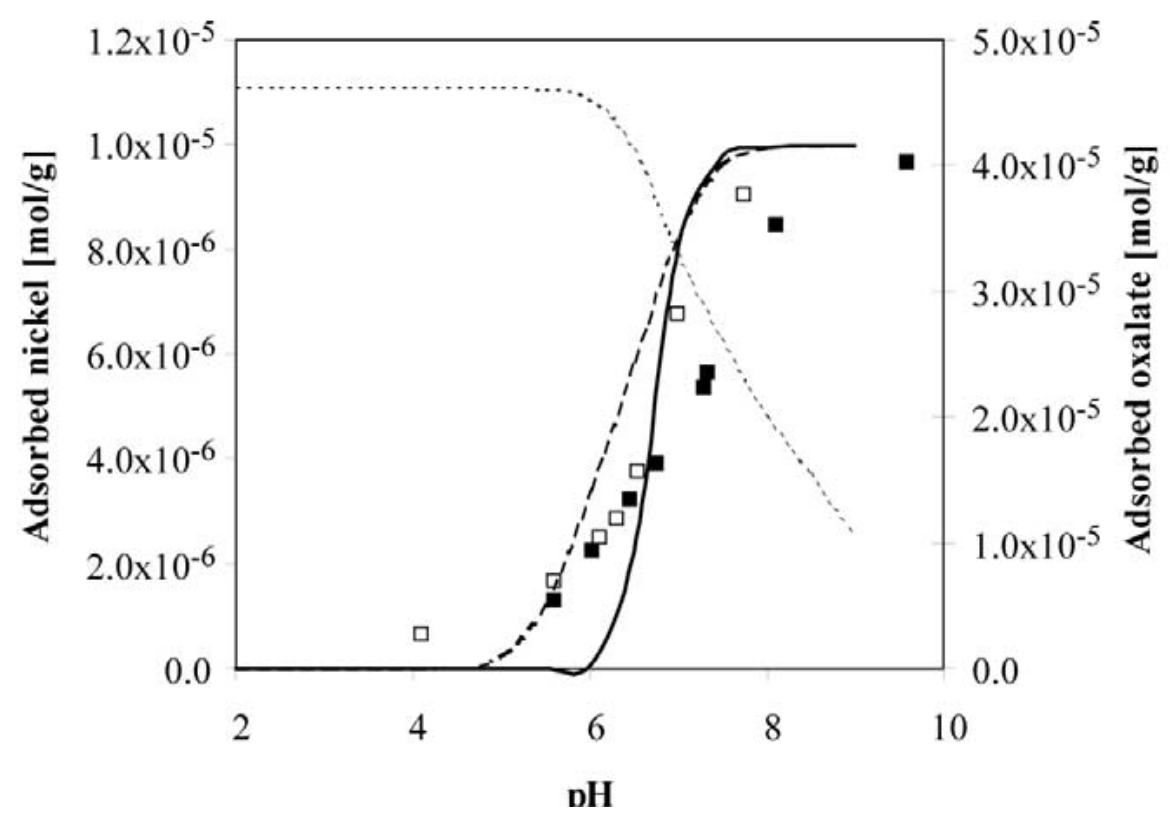

Figure 2. $\mathrm{pH}$ adsorption-edge of $\mathrm{Ni}$ in the presence of oxalate (ם). For comparison, a reference experiment in $0.01 \mathrm{M} \mathrm{KNO}_{3}(\square)$, calculated with the SCM and the DLM (----) is shown. The calculated (- - - - -) oxalate adsorption-edge in the presence of $\mathrm{Ni}$ is represented. $\mathrm{Ni}$ adsorption in the presence of oxalate was calculated by approach 1 (—).

\subsection{INFLUENCE OF SALICYLATE ON THE ADSORPTION OF CU, NI, AND CD ON GOETHITE (FIGURES 4-6)}

For the three metals, no clear influence of salicylate on metal adsorption could be observed (Figures 4 and 5). Only $\mathrm{Cd}$ adsorption was enhanced in the presence of salicylate between pH 5 and 7 (Figure 6). Calculating copper adsorption on goethite in the presence of salicylate by approach 1 underestimated the adsorption at $\mathrm{pH}$ values above 5 . Defining a ternary complex of type $\mathrm{A}\left(\log K_{\mathrm{ter}, \mathrm{A}}=10\right)$ (approach 2) helped to explain the data.

The calculated nickel adsorption-edges in the absence and in the presence of salicylate lay over each other, showing that complexation by salicylate did not effectively compete with surface binding.

The elevated adsorption of $\mathrm{Cd}$ in the acidic range indicated additional interactions which could not be readily modeled. No competition effect at high $\mathrm{pH}$ values was observed. 


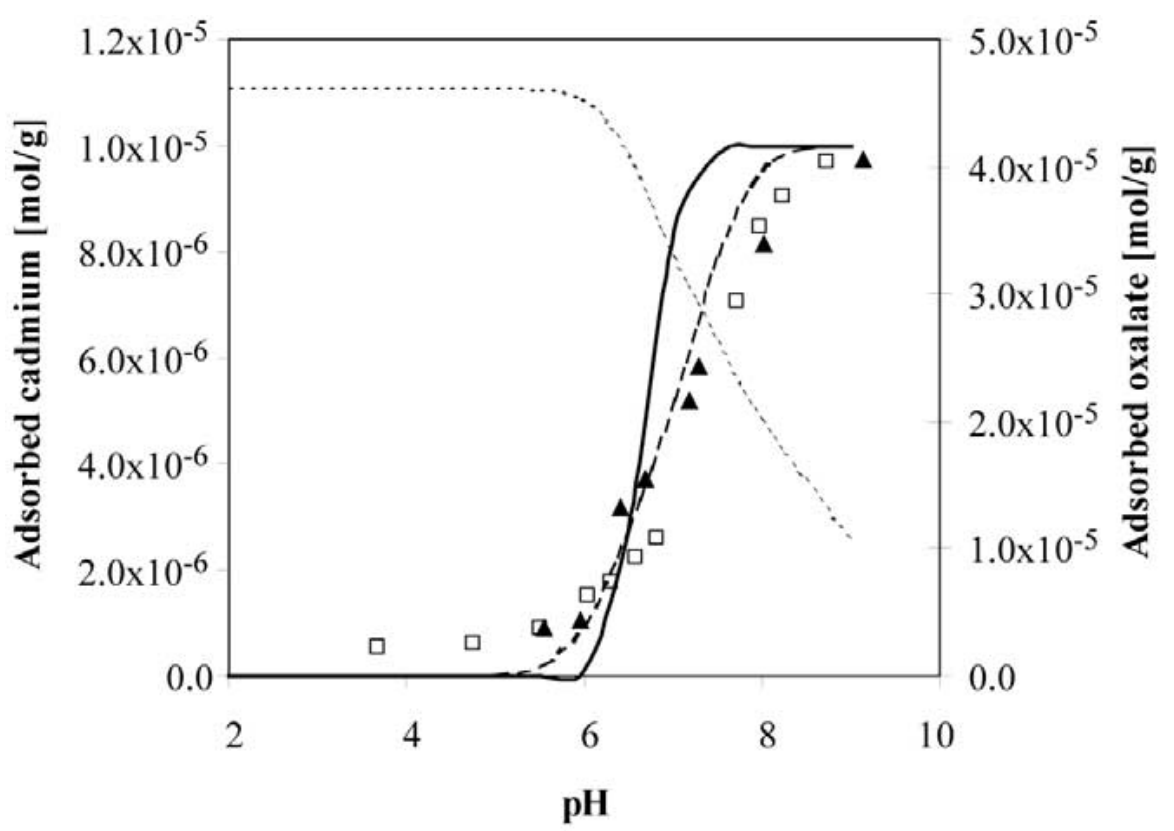

Figure 3. $\mathrm{pH}$ adsorption-edge of $\mathrm{Cd}$ on goethite in the presence of oxalate $(\boldsymbol{\Lambda})$. A reference experiment performed in $0.01 \mathrm{M} \mathrm{KNO}_{3}(\square)$, could be described by the SCM and the DLM (----). The calculated oxalate adsorption-edge in the presence of $\mathrm{Cd}$ is represented (- - - - ). Cd adsorption in the presence of oxalate was calculated with approach 1 (-

\subsection{INFLUENCE OF PYROMELLITATE ON THE ADSORPTION OF CU, NI, AND CD ON GOETHITE (FIGURES 7-9)}

Essentially no decrease in $\mathrm{Cu}$ and $\mathrm{Ni}$ adsorption by pyromellitate could be observed at high $\mathrm{pH}$ values, which is contrary to what would be expected as pyromellitate is a strong complexant. At $\mathrm{pH}$ values between 4 and 5, however, the adsorption of $\mathrm{Cu}$ was clearly enhanced in the presence of pyromellitate compared to the reference system (Figure 7). This effect was not observed for Ni. Increasing pyromellitate concentration did neither enhance $\mathrm{Ni}$ adsorption in the acidic $\mathrm{pH}$ range, nor suppress Ni adsorption (Figure 8).

In the calculations (approach 1), no difference was found in the copper adsorption in the absence or in the presence of pyromellitate. The effect of complexation in solution by pyromellitate is compensated by the electrostatic attraction due to the adsorbed pyromellitate (Figure 7). At $\mathrm{pH}$ values between 4 and 5, copper adsorption was better described by assuming the formation of a ternary surface complex of type $\mathrm{B}, \equiv F e-P y r-C u^{-}\left(\log K_{\text {ter }, \mathrm{B}}=17.5\right)($ approach 2$)$.

Calculations were not done for Ni because no complexation constants for pyromellitate with $\mathrm{Ni}$ were found in the literature, but similar constants as with $\mathrm{Cu}$ can be expected. It seems likely that, in a similar way as for $\mathrm{Cu}$, electrostatic attractions 


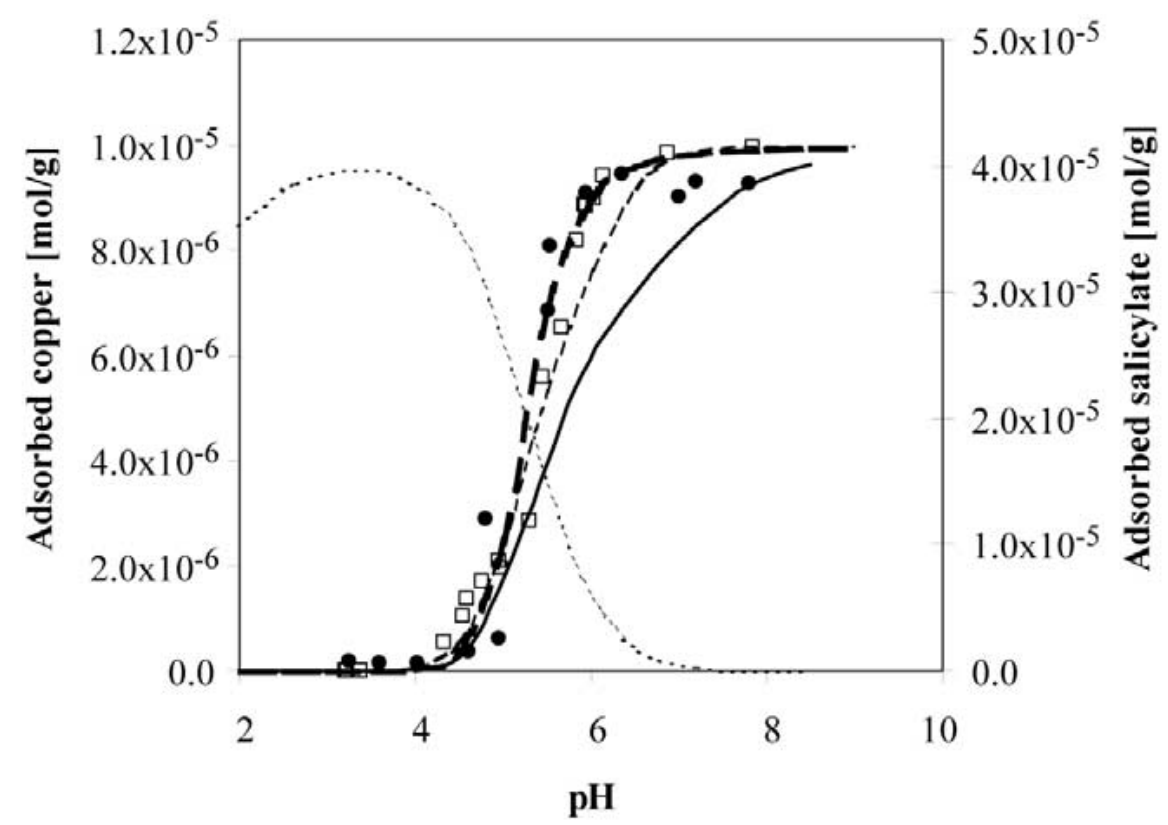

Figure 4. pH adsorption-edge of $\mathrm{Cu}$ on goethite in the presence of salicylate ()). For comparison, a reference experiment in $0.01 \mathrm{M} \mathrm{KNO}_{3}(\square)$, calculated with the SCM and the DLM $(---)$ is shown. The calculated adsorption-edge of salicylate in the presence of copper is also shown (- - - ). Cu adsorption in the presence of salicylate were calculated with approach 1 (-) and 2 (-- - ). The formation of the ternary surface complex of type A, $\equiv \mathrm{Fe}-\mathrm{O}-\mathrm{Cu}-\mathrm{Sal}^{-}$, was assumed and the constant used for calculation was $\log \mathrm{K}_{\mathrm{ter}, \mathrm{A}}=10$.

compensate the complexation of $\mathrm{Ni}$ by pyromellitate in solution and/or that ternary surface complexes are formed (Figure 8).

A significant enhancement of the Cd adsorption was observed for $\mathrm{pH}$ values between 5 and 7 (Figure 9). The calculations by approach 1 also showed an enhanced adsorption of $\mathrm{Cd}$ in the presence of pyromellitate, because the electrostatic attractions outcompete the complexation of $\mathrm{Cd}$ in solution. If a ternary complex of type B $\left(\log K_{\text {ter, }}=16\right)$ is assumed, the adsorption-edge becomes less steep, and the experimental curve is better described. Formation of a ternary complex is possible, in a similar way as for $\mathrm{Cu}$.

\section{Discussion}

Based on experimental data and calculations, it appears that the competitive reactions and the formation of ternary complexes on the goethite surface represent the major influences of the ligands on metal adsorption. 


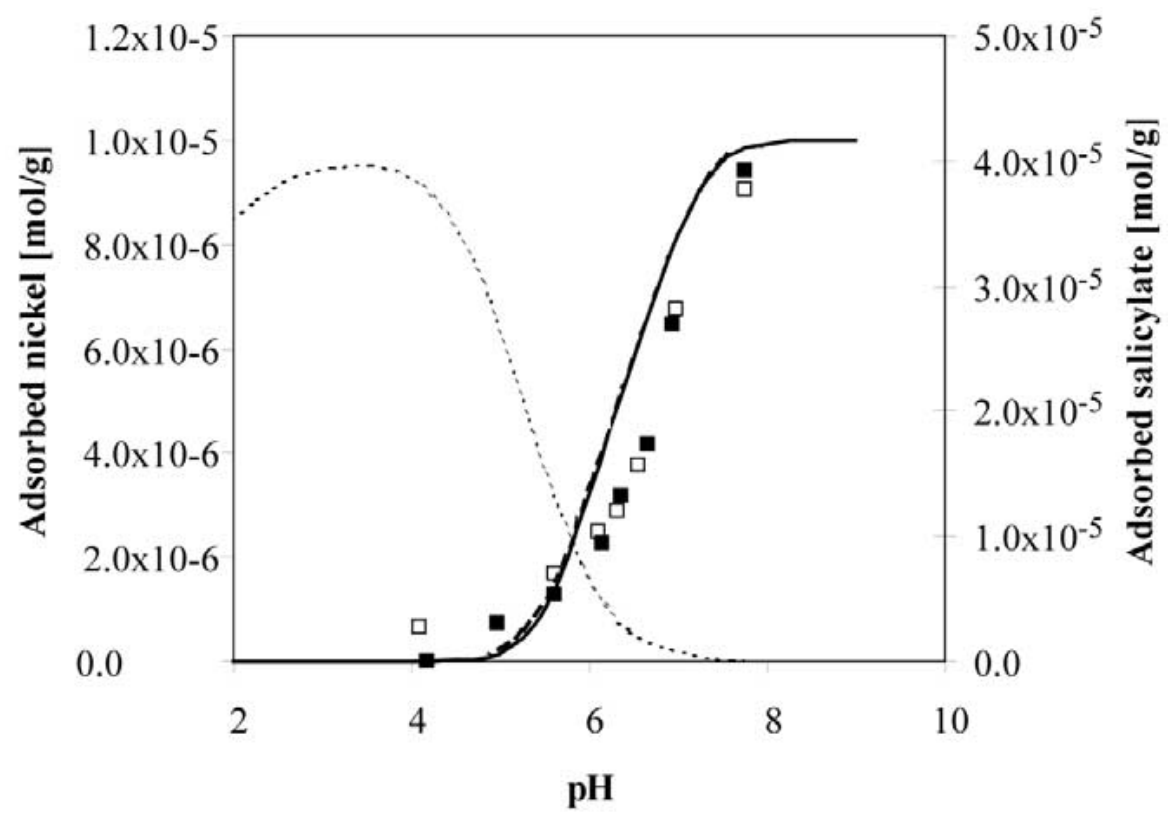

Figure 5. pH adsorption-edge of $\mathrm{Ni}$ on goethite in the presence of salicylate ( $\mathbf{\square})$. The reference experiment in $0.01 \mathrm{M} \mathrm{KNO}_{3}(\square)$, calculated with the SCM and the DLM (----), and the calculated adsorption-edge of salicylate (--.--) are also shown. Ni adsorption in the presence of salicylate was calculated with approach 1 (—). The calculated adsorption-edge by approach 1 and the reference adsorption-edge lie on each other.

\subsection{INFLUENCE OF THE COMPETITIVE REACTIONS}

Competition for complexation of $\mathrm{Cu}$ (and $\mathrm{Ni}$ ) between the surface groups and oxalate or pyromellitate in solution clearly decreased metal adsorption at $\mathrm{pH}$ values above 6 according to the calculations. In the presence of oxalate, this decrease was more pronounced, because oxalate is the stronger complexant. A decrease in the adsorption of $\mathrm{Cu}$ on soil in the presence of oxalate has been observed also in a previous work (Kumar and Fish, 1996), in which $\mathrm{Cu}$ concentrations were varied between $15 \mu \mathrm{M}$ and $121 \mu \mathrm{M}$ and oxalate concentrations between 100 and $1000 \mu \mathrm{M}$. An increased ratio of oxalate to $\mathrm{Cu}$ concentration induced a shift of the adsorption-edge to the right, i.e., a decrease in $\mathrm{Cu}$ adsorption for a given $\mathrm{pH}$.

In contrast to these systems, no significant effect of oxalate and pyromellitate could be observed in the $\mathrm{Cd}$ system. Cd forms less stable complexes with carboxylic groups than $\mathrm{Cu}$ and $\mathrm{Ni}$ and is preferentially complexed by the goethite surface functional groups. Similar results for Cd adsorption on soil samples and goethite in the presence of oxalate at high $\mathrm{pH}$ values were reported in previous works (Elliott and Denneny, 1982; Lamy et al., 1991; Naidu and Harter, 1998).

Salicylate, which is a weak ligand compared to oxalate and pyromellitate, did not have a pronounced influence on the adsorption of $\mathrm{Cd}$ and Ni. A slight decrease 


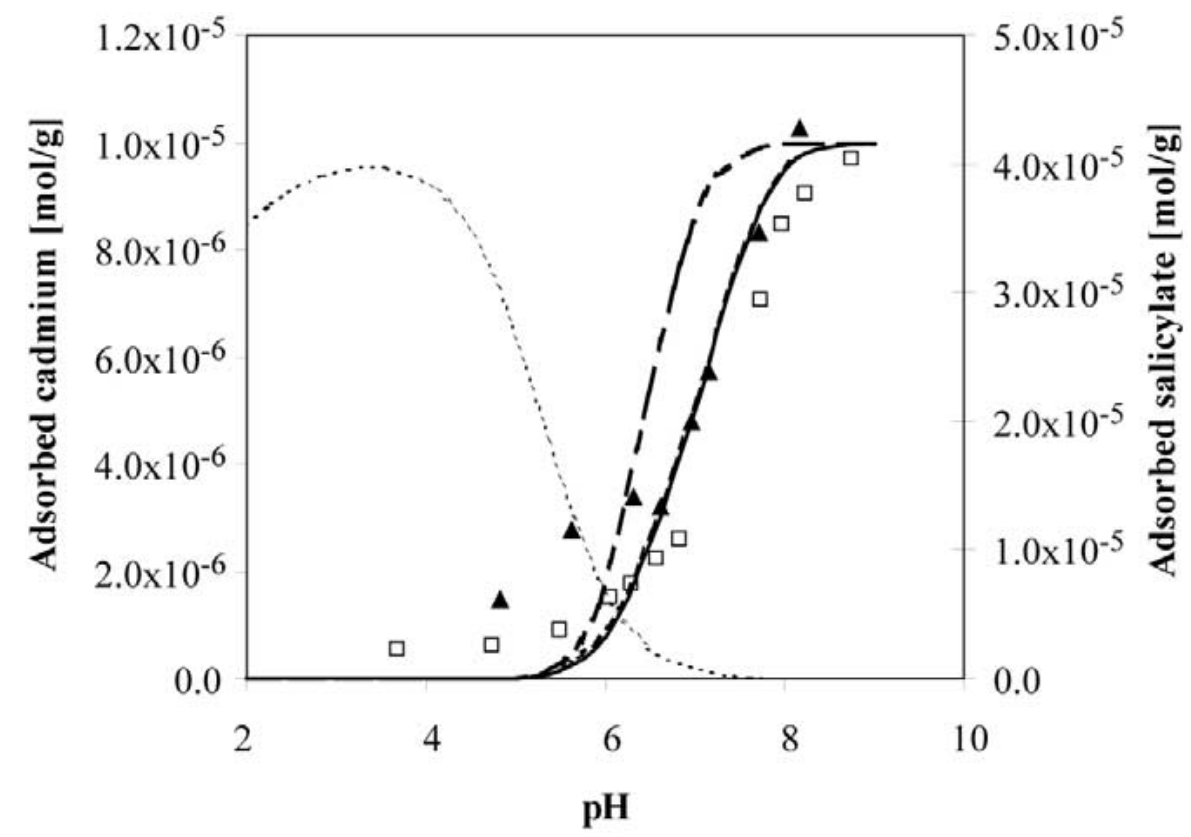

Figure 6. $\mathrm{pH}$ adsorption-edge of $\mathrm{Cd}$ on goethite in the presence of salicylate $(\mathbf{\Lambda})$. For comparison, a reference experiment in $0.01 \mathrm{M} \mathrm{KNO}_{3}(\square)$, calculated with the SCM and the DLM (----) is shown. The calculated adsorption-edge of salicylate in the presence of $\mathrm{Cd}$ is also shown (-----). Cd adsorption in the presence of salicylate was calculated with approach 1 (-), and 2 (---). The formation of the ternary surface complex of type A, $\equiv \mathrm{Fe}-\mathrm{O}-\mathrm{Cd}-\mathrm{Sal}^{-}$, was assumed and the constant used for the adsorption constant used for the calculations was $\log \mathrm{K}_{\mathrm{ter}, \mathrm{A}}=8$. The calculated adsorption-edge by approach 1 and the reference adsorption-edge lie on each other.

in adsorption was only found for $\mathrm{Cu}$ at $\mathrm{pH}$ values above 7. Davies and Leckie (Davis and Leckie, 1978) have investigated $\mathrm{Cu}$ adsorption $\left(10^{-6} \mathrm{M}\right)$ on amorphous iron $\left(10^{-3} \mathrm{M}\right)$ in the presence of salicylate $\left(10^{-4} \mathrm{M}\right)$. They have also found no difference in $\mathrm{Cu}$ adsorption in the absence and in the presence of salicylate.

\subsection{FORMATION OF TERNARY SURFACE COMPLEXES}

In the presence of pyromellitate, the adsorption of $\mathrm{Cu}$ was enhanced at low $\mathrm{pH}$ values, which could be adequately described by the definition of a ternary surface complex of type B. Ternary surface complexes are possible in this system from the structural as well as from the chemical point of view. Evidence for innersphere pyromellitate surface complex formation at $\mathrm{pH}$ values below 6 has been given in the literature by infrared spectra (Boily et al., 2000). Pyromellitate adsorbs on the goethite surface by binding with 2 carboxylic groups, and thus formation of ternary surface complexes of type B is possible as the two carboxylic groups on the opposite side of the ring can still complex metals. Additional insights may be gained 


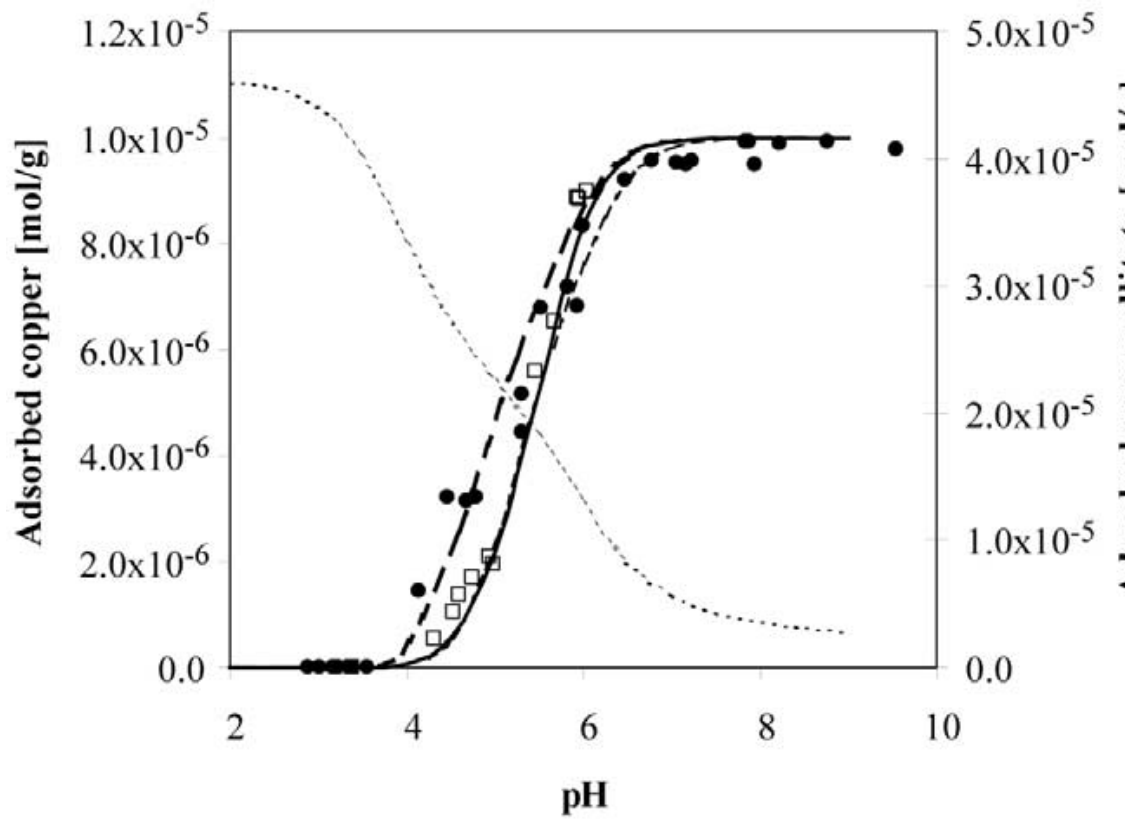

Figure 7. $\mathrm{pH}$ adsorption-edge of $\mathrm{Cu}$ on goethite in the presence of pyromellitate $(\bullet)$. A reference adsorption-edge in $0.01 \mathrm{M} \mathrm{KNO}_{3}(\square)$, calculated with the SCM and the DLM (----), is shown for comparison. The calculated adsorption-edge of pyromellitate in the presence of $\mathrm{Cu}$ (- - - - - ) is represented as well. $\mathrm{Cu}$ adsorption in the presence of pyromellitate was calculated by approach 1 (—). The ternary surface complex (approach 2 ) of type $\mathrm{B}, \equiv \mathrm{Fe}-\mathrm{Pyr}-\mathrm{Cu}^{-}$ (-- - ), with an adsorption constant of $\log \mathrm{K}_{\mathrm{ter}, \mathrm{B}}=17.5$, has to be assumed in order to represent the experimental data.

by comparing the $\mathrm{pH}$-range of the complexation of $\mathrm{Cu}$ by pyromellitate and by the surface groups (Figure 10a). At $\mathrm{pH}$ values below 5, $\mathrm{Cu}$ forms complexes with dissolved pyromellitate. However, at this $\mathrm{pH}$, an important fraction of pyromellitate is adsorbed on goethite. It seems thus likely that ternary surface complexes of type $\mathrm{B}$ may be formed in this $\mathrm{pH}$-range.

The enhanced adsorption of $\mathrm{Cu}$ in the presence of salicylate could be explained by assuming formation of ternary surface complexes of type A. Ternary surface complexes of type B are unlikely with salicylate because of the unfavorable position of the functional groups. CIR- and ATR-FTIR (cylindrical internal reflection and attenuated total reflection, respectively, Fourier transform infrared) measurements showed that salicylate adsorbs on goethite by forming a six-membered ring, which involves one oxygen atom from the carboxylic group, one from the phenolic group and one Fe atom from the surface (Biber and Stumm, 1994; Yost et al., 1990). No functional group remains free to complex a metal cation in such a structure. The comparison of the $\mathrm{pH}$-ranges of aqueous and surface complexation indicates that $\mathrm{Cu}$-salicylate aqueous complexes are only formed at $\mathrm{pH}$ values higher than the $\mathrm{Cu}$-goethite surface complexes (Figure 10b). 


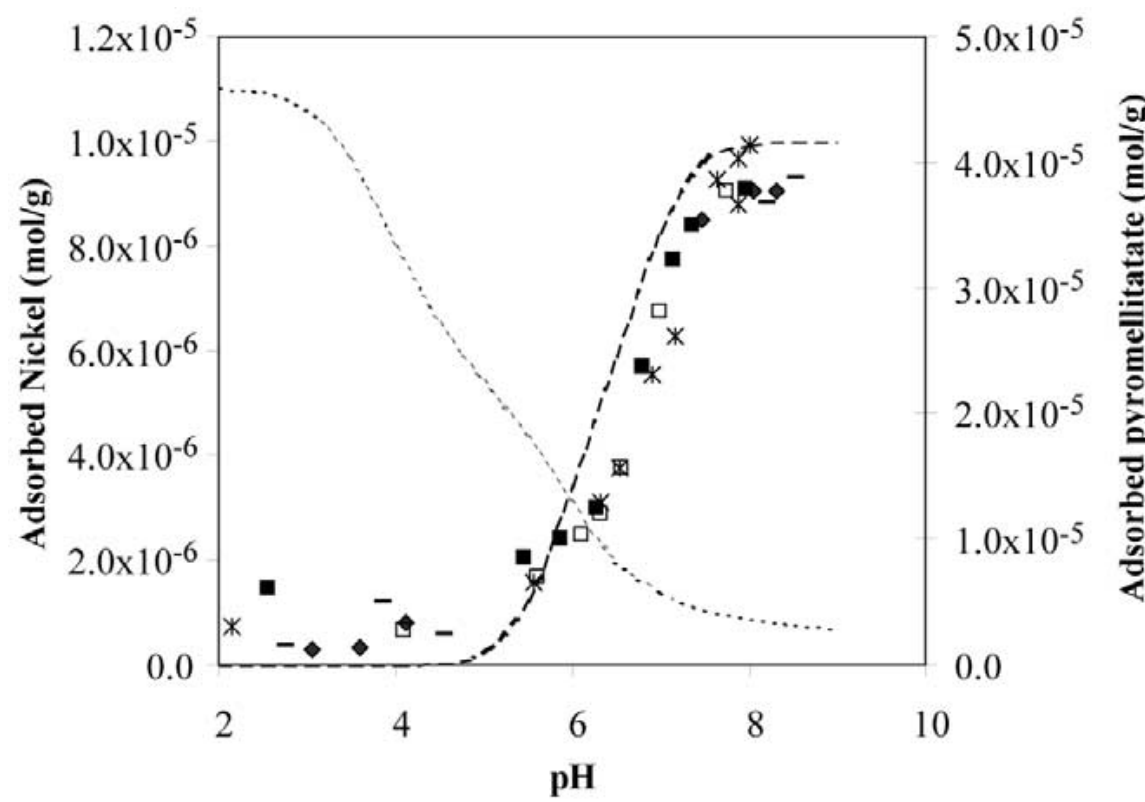

Figure 8. $\mathrm{pH}$ adsorption-edge of $\mathrm{Ni}$ on goethite in the presence of pyromellitate. Different concentrations of pyromellitate were used: $5 \times 10^{-4} \mathrm{M}(\boldsymbol{\square}), 7.44 \times 10^{-4} \mathrm{M}(-), 1 \times 10^{-3}$ $\mathrm{M}(*)$. Ni concentrations were always $5 \times 10^{-6} \mathrm{M}$. A reference adsorption-edge, performed in $0.01 \mathrm{M} \mathrm{KNO}_{3}(\square)$, was calculated with the SCM together with the DLM (----). The calculated adsorption-edge of pyromellitate (concentration: $\left.\left.5 \times 10^{-4} \mathrm{M}\right)(---)_{-}\right)$is also shown. Further calculations were not possible, as the aqueous complexation constants of $\mathrm{Ni}$ by pyromellitate are not available.

The adsorption of $\mathrm{Cd}$ was enhanced in the acidic $\mathrm{pH}$ range by salicylate and pyromellitate. In the pyromellitate system, the definition of ternary surface complexes of type $\mathrm{B}$ could explain the enhanced $\mathrm{Cd}$ adsorption on goethite at $\mathrm{pH}$ values around 5. In a similar way as for $\mathrm{Cu}$, the $\mathrm{Cd}$-pyromellitate aqueous complexes are formed at $\mathrm{pH}$ values below 6 (Figure 10c). So the enhanced $\mathrm{Cd}$ adsorption in this $\mathrm{pH}$ region may be due to the formation of ternary surface complexes of type B. A similar statement can be made in the Cd-salicylate system (Figure 10d). However, in this system, the formation of ternary surface complexes of type B is unlikely due to the structure of adsorbed salicylate, and outersphere surface complexes may rather be present. Enhanced Cd adsorption in the presence of organic ligands was reported previously in several studies (Benyahya and Garnier, 1999; Lamy et al., 1991; Naidu and Harter, 1998). It was mainly assumed to be due to the formation of ternary surface complexes (Benyahya and Garnier, 1999; Naidu and Harter, 1998).

Oxalate adsorbs most probably on the goethite surface by forming a fivemembered ring or by forming a surface complex with two iron atoms (Hug, 1994; Parfitt et al., 1977). These structures, however, are not favorable for the formation of ternary surface complexes of type B as the two carboxylic groups are involved 


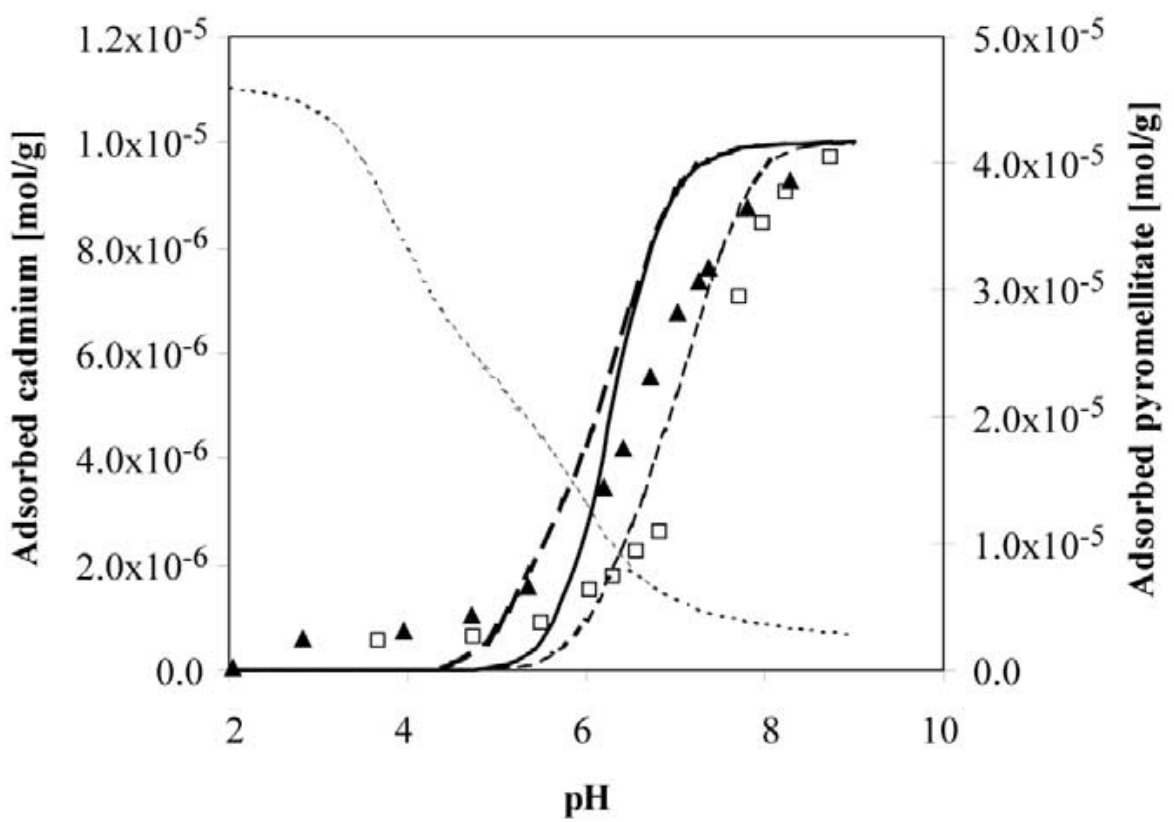

Figure 9. $\mathrm{pH}$ adsorption-edge of $\mathrm{Cd}$ on goethite in the presence of pyromellitate $(\boldsymbol{\Delta})$. A reference adsorption-edge in $0.01 \mathrm{M} \mathrm{KNO}_{3}(\square)$, calculated with the SCM and the DLM (----), is shown for comparison. Furthermore the calculated adsorption-edge of pyromellitate in the absence of $\mathrm{Cd}\left(---_{---)}\right)$is shown. Cd adsorption in the presence of pyromellitate was calculated by approach 1 (—). Assuming the ternary complex of type B (approach 2), $\equiv \mathrm{Fe}-\mathrm{Pyr}-\mathrm{Cd}^{-}$ (-- - ), with an adsorption constant $\log \mathrm{K}_{\mathrm{ter}, \mathrm{B}}=16$, does not improve the calculations.

in the complex structure. Other surface complexes, in which oxalate adsorbs only with one carboxylic group, as those defined for oxalate adsorption on $\mathrm{TiO}_{2}$, are possible (Hug, 1994), but they are less stable.

\section{Summary and Outlook}

In this work, we analyzed the influence of organic ligands on metal adsorption in nine different systems. This approach allowed direct comparison of the adsorption behavior of the different metals in presence of organic ligands. The position and slope of the metal edge gave valuable information on the possible influence of the ligands. The different behaviors were discussed in detail, and simple calculations with reasonable assumptions were used to corroborate the qualitative interpretation of the data. The combination of experimental data and simple calculations indicates that the most important effects are: (i) oxalate competes effectively with surface adsorption by forming aqueous complexes in solution, (ii) salicylate has little influence on trace metal adsorption; and (iii) pyromellitate likely forms ternary surface complexes and thus enhances adsorption in the acidic $\mathrm{pH}$-range. These effects are consistent with the complexation properties and the structures of the 


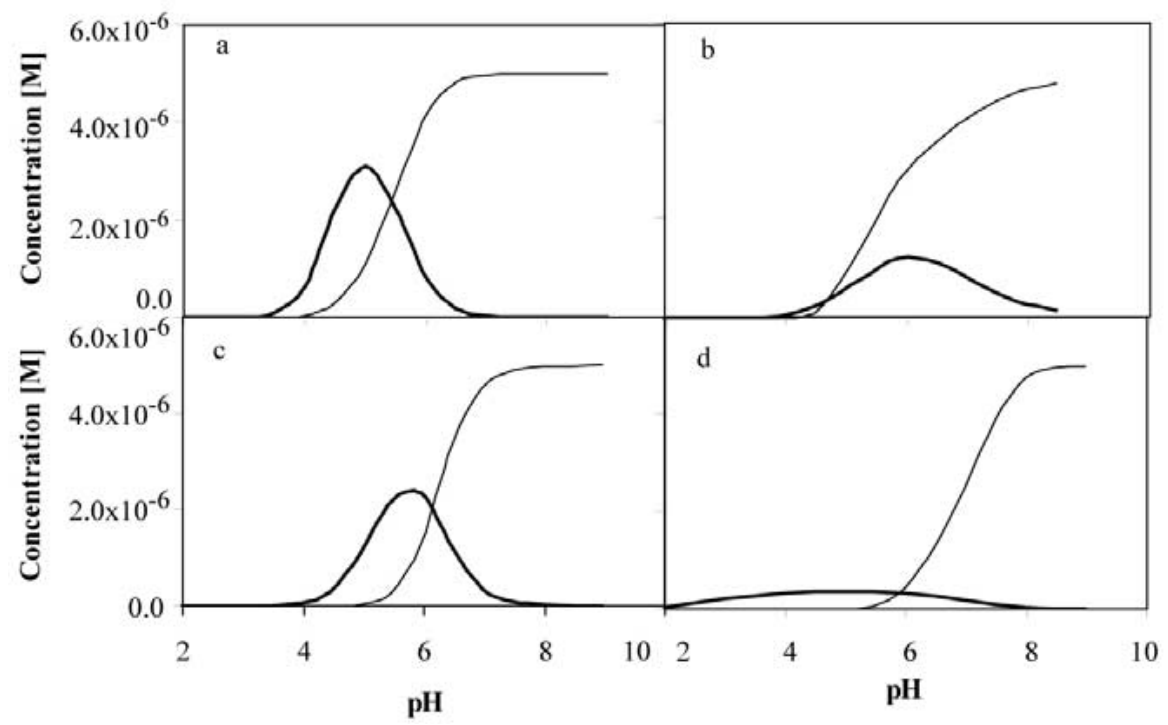

Figure 10. Representation of the metal-ligand complexes in solution and the metal-goethite complexes in function of $\mathrm{pH}$ for different systems. The thick line represents the aqueous metal-ligand complexes, and the thin line represents the copper- or cadmium-goethite surface complexes. (a) Cu-pyromellitate system; (b) Cu-salicylate system; (c) Cd-pyromellitate system; (d) Cd-salicylate system.

ligands. Moreover, ternary surface complexation formation of type A could help to better describe $\mathrm{Cu}$ adsorption on goethite in the presence of oxalate and salicylate. Thus, these experiments show that ternary surface complexation formation may be important in most of the metal-organic acid-goethite systems (Ali and Dzombak, $1996 b, c)$.

Adsorption constants and constants defined for the ternary complexes formed in this system have to be considered with care, as they represent only conditional constants linked to the system that was studied. Constants that are more general could be determined by broadening the experimental conditions (i.e., varying concentrations of sorbent, metal ion and ligand, use of different ionic strengths). However, for more extensive modeling, detailed mechanistic information would be needed. Surface spectroscopic and microscopic measurements would provide more information about innersphere or outersphere surface complexes and the formation of ternary surface complexes.

\section{Acknowledgements}

We thank Adrian Ammann, Thomas Rüttiman, and David Kistler for help with analytical measurements, and Bernhard Wehrli for discussions. BASF goethite was provided through the GDR Practis (CNRS, CEA, EdF, Andra). Thanks to three anonymous reviewers for valuable suggestions. 


\section{References}

Aiken G. R., McKnight D. M., Wershaw R. L. and Mac Carthy P. (1985) Humic Substances in Soil, Sediment, and Water. Geochemistry, Isolation, and Characterization. John Wiley \& Sons, New York.

Ali M. and Dzombak D. A., (1996a) Competitive sorption of simple organic acids and sulfate on goethite. Environ. Sci. Technol. 30(4), 1061-1071.

Ali M. and Dzombak D. A. (1996b) Interaction of copper, organic acid, and sulfate in goethite suspensions. Geochim. Cosmochim. Acta 60, 5045-5053.

Ali M. and Dzombak D. A. (1996c) Effects of simple organic acids on sorption of $\mathrm{Cu}^{2+}$ and $\mathrm{Ca}^{2+}$ on goethite. Geochim. Cosmochim. Acta 60, 291-304.

Angove M. J., Wells J. D. and Johnson B. B. (1999) Adsorption of cadmium(II) onto goethite and kaolinite in the presence of benzene carboxylic acids. Colloid Surface A 146, 243-251.

Bartschat B. M., Cabaniss S. E. and Morel F. M. M. (1992) Oligoelectrolyte model for cation binding by humic substances. Environ. Sci. Technol. 26(2), 284-294.

Benedetti M. F., Milne C. J., Kinniburgh D. G., van Riemsdijk W. H. and Koopal L. K. (1995) Metal ion binding to humic substances: Application of the non-ideal competitive adsorption model. Environ. Sci. Technol. 29(2), 446-457.

Benyahya L. and Garnier J.-M. (1999) Effect of salicylic acid upon trace-metal sorption (Cd(II), $\mathrm{Zn}(\mathrm{II}), \mathrm{Co}(\mathrm{II})$, and $\mathrm{Mn}(\mathrm{II})$ ) onto alumina, silica, and kaolinite as a function of pH. Environ. Sci. Technol. 33(9), 1398-1407.

Biber M. and Stumm W. (1994) An in-situ ATR-FTIR study: The surface coordination of salicylic acid on aluminium and iron(III) oxides. Environ. Sci. Technol. 28(5), 763-768.

Boily J.-F. (1999) A Refined Multisite Complexation Model for Cd(II) Surface Complexes on Goethite Particles of different Surface Areas. Ph.D. thesis, Umeå University, Sweden.

Boily J.-F., Nilsson N., Persson P. and Sjöberg S. (2000) Benzenecarboxylate surface complexation at the goethite/water interface: I. A mechanistic description of pyromellitate surface complexes from the combined evidence of infrared spectroscopy, potentiometry, adsorption data, and surface complexation modeling. Langmuir 16, 5719-5729.

Davis J.A. and Leckie J.O. (1978) Effect of adsorbed complexing ligands on trace metal uptake by hydrous oxides. Environ. Sci. Technol. 12, 1309-1315.

Dzombak D. A., Fish W. and Morel F. M. M. (1986) Metal-humate interactions. 1. Discrete ligand and continuous distribution models. Environ. Sci. Technol. 20(7), 669-675.

Dzombak D. A. and Morel F. M. M. (1990) Surface Complexation Modeling. Hydrous Ferric Oxide. John Wiley \& Sons, New York.

Ehrhardt J. J. (ed.), (1999) Proceedings of the Meeting on 'Réactivité de surface de goethites'. Organisation GDR CNRS PRACTIS. Laboratoire de Chimie Physique pour l'Environnement, Nancy.

Elliott H. A. and Denneny C. M. (1982) Soil adsorption of cadmium from solutions containing organic ligands. J. Environ. Qual. 11(4), 658-662.

Evanko C. R. and Dzombak D. A. (1998) Influence of structural features on sorption of NOManalogue organic acids to goethite. Environ. Sci. Technol. 32(19), 2846-2855.

Evanko C. R. and Dzombak D. A. (1999) Surface complexation modeling of organic acid sorption to goethite. J. Colloid Interface Sci. 214, 189-206.

Filius J. D., Hiemstra T. and Van Riemsdijk W. H., (1997) Adsorption of Small Weak Organic Acids on Goethite: Modeling of Mechanisms. J. Colloid Interface Sci. 195, 368-380.

Giammar D. E. and Dzombak D. A., (1998) Copper complexation with the mellitic acid series. Journal of Solution Chemistry 27(1), 89-105.

Gu B., Schmitt J., Chen Z., Liang L. and McCarthy H. F. (1994) Adsorption and desorption of natural organic matter on iron oxide: Mechanisms and models. Environ. Sci. Technol. 28, 38-46. 
Herbelin, A. and Westall, J. (1994) FitEQL. A computer program for determination of chemical equilibrium constants from experimental data. Version 3.1. Department of Chemistry, Oregon State University. Corvallis, Oregon 97331.

Huang C. P., Elliott H. A., Ashmead R. M. (1977) Interfacial reactions and the fate of heavy metals in soil-water systems. Water Pollution Control Federation 745-756.

Hug S. and Sulzberger B. (1994) In Situ Fourier transform infrared spectroscopic evidence for the formation of several different surface complexes of oxalate on $\mathrm{TiO}_{2}$ in the aqueous phase. Langmuir 10, 3587-3597.

Kumar A. and Fish W. (1996) Ligands, metals, and metal-ligand complexes as differential probes of soil adsorptive heterogeneity. Colloid Surface A 107, 111-122.

Lamy I., Djafer M. and Terce M. (1991) Influence of oxalic acid on the adsorption of cadmium at the goethite surface. Water, Air, Soil Poll. 57-58, 457-465.

Leenheer J. A., Wershaw R. L. and Reddy M. M. (1995) Strong-acid, carboxylic-group structures in fulvic acid from the Suwannee River, Georgia. 1. Minor structures. Environ. Sci. Technol. 29(2), 393-398.

Martell A. E., Smith R. M. (2001) NIST Critically Selected Stability Constants of Metal Complexes. NIST Standard Reference Database 46 Version 6.0.

Mash H. E., Chin Y., Sigg L., Hari R. and Xue H., (2003) Complexation of copper by zwitterionic aminosulfonic (good) buffers. Anal. Chem. 75, 671-677.

Mesuere K. and Fish W. (1992) Chromate and Oxalate Adsorption on Goethite: 1. Calibration of Surface Complexation Models. Environ. Sci. Technol. 26(12), 2357-2370.

Morsad H., (1999) Caractérisation physico-chimique d'un sable de quartz et d'un oxyhydroxyde de fer. Report-DEA “Chimie et Microbiologie de l'eau (Université Poitiers, Pau, Nancy)-Institut de Mécanique des Fluides, Université Louis Pasteur, Strasbourg.

Müller B., (1996) ChemEQL A Program to Calculate Chemical Speciation, Equilibrium, Titrations, Dissolution, Precipitation, Adsorption, Simple Kinetics, pX-pY Diagrams. Version 2.0. EAWAG Kastanienbaum (Switzerland).

Naidu R. and Harter R. D. (1998) Effect of different organic ligands on cadmium sorption by and extractability from soils. Soil. Sci. Soc. Am. J. 62, 644-650.

Öhman L.-O. and Sjöberg S. (1996) The experimental determination of thermodynamic properties for aqueous aluminium complexes. Coordin. Chem. Rev. 149, 33-57.

Parfitt R. L., Fraser A. R., Russell J. and Farmer V. C. (1977) Adsorption on hydrous oxides II. Oxalate, benzoate and phosphate on gibbsite. J. Soil Sci. 28, 40-47.

Robertson A. P. (1998) Acid/Base, Copper Binding, and $\mathrm{CU}^{++} / \mathrm{H}^{+}$Exchange Properties of Goethite, an Experimental and Modelin Study. Environ. Sci. Technol. 32(17), 2519-2530.

Siffert C. and Sulzberger B. (1991) Light-induced dissolution of hematite in the presence of oxalate: A case study. Langmuir 7(8), 1627-1634.

Smith R. M. and Martell A. E. (1976) Critical Stability Constants. Vol. 4: Inorganic Complexes. Plenum Press, New York.

Smith R. M. and Martell A. E. (1977) Critical Stability Constants. Vol. 3: Other Organic Ligands. Plenum Press, New York.

Smith R. M. and Martell A. E., (1982) Critical Stability Constants. Vol. 5: First Supplement. Plenum Press, New York.

Stevenson F. J. (1982) Humus Chemistry: Genesis, Composition, Reactions. John Wiley and Sons, Inc., New York.

Stumm W. (1996) Chemistry of the Solid-Water Interface. John Wiley and Sons, New York.

Stumm W. and Morgan J. J. (1996) Aquatic Chemistry. John Wiley and Sons, New York.

Sulzberger B., Suter D., Siffert C., Banwart S. and Stumm W. (1989) Dissolution of Fe(III) (hydr)oxides in natural waters; laboratory assessment on the kinetics controlled by surface coordination. Mar. Chem. 28, 127-144. 
Tipping E. (1986) Some aspects of the interactions between particulate oxides and aquatic humic substances. Mar. Chem. 18, 161-169.

Tipping E. (1993) Modelling ion binding by humic acids. Colloid Surface A 73, 117-131.

Tipping E. (1994) WHAM-A chemical equilibrium model and computer code for waters, sediments, and soils incorporating a discrete site/electrostatic model of ion-binding by humic substances. Comput. Geosci. 20(6), 973-1023.

Tipping E. and Hurley M. A. (1992) A unifying model of cation binding by humic substances. Geochim. Cosmochim. Acta 56, 3627-3641.

Tipping E. and Woof C. (1990) Humic substances in acid organic soils: Modelling their release to the soil solution in terms of humic charge. J. Soil Sci. 41, 573-586.

Venema P., Hiemstra T. and van Riemsdijk W. H. (1996) Multisite adsorption of cadmium on goethite. J. Colloid Interface Sci. 183, 515-527.

Violante A., Rao M. A., De Chiara A. and Gianfreda L. (1996) Sorption of phosphate and oxalate by a synthetic aluminium hydroxylsulphate complex. Europ. J. Soil Sci. 47, 241-247.

von Gunten H. R., Karametaxas G., Kraehenbuehl U., Kuslys M., Giovanoli R., Hoehn E. and Keil R. (1991) Seasonal biogeochemical cycles in riverborne groundwater. Geochim. Cosmochim. Acta $\mathbf{5 5}, 3597-3609$.

von Gunten H. R. and Kull T. P. (1986) Infiltration of inorganic compounds from the Glatt River, Switzerland, into a groundwater aquifer. Water Air Soil Poll. 29, 333-346.

von Gunten H. R. and Lienert C. (1993) Decreased metal concentrations in ground water caused by controls of phophate emissions. Nature 364, 220-222.

Weirich D., (2000) Influence of Organic Ligands on the Adsorption of Copper, Cadmium, and Nickel on Goethite. Diss. ETH No. 13917. Ph.D. thesis., Zürich.

Yost E. C., Tejedor-Tejedor M. I. and Anderson M. A. (1990) In situ CIR-FTIR characterization of salicylate complexes at the goethite/aqueous solution interface. Environ. Sci. Technol. 24(6), 822-828. 
